\title{
Conditioned Unification for Natural lánguage Processing
}

\author{
Kồiti Hastidla \\ Hectrotcchmical labewatory \\ Unezono 1-1-4. Sakura-Mura, Nibari-Gun. \\ Tharaki, 30h Japar
}

\section{ABS'TRAC'T}

This paper presents what we call a conditioned unification, a new method of unification for processing natural languages. The key idea is to annotate the patterns with a certain sort of conditions, so that they carry abundant information. This method transmits information from one patlem to another more efliciently than procodure attachments, in which information contained in the procedure is embedded in the program rather than directly attached to patterns. Coupled with techniques in formal linguistics, moreover, conditioned unification serves most types of operations for natural language processing.

\section{Introduction}

$\Lambda$ current major trend of natural language processing is characterized by the overatl use of unification (Shicber (1984), Kay (1985), Proudin and l'ollard (1985), P'ereira (1985), Shicber (1085) ), ote) reflecting the recent developments in nontransformational lingustic formalisms, such as Jexical Functional Grammar (Bresnan (1982)), Generalized Phrase Strueture Grammar (GPSG) (Ga\%har, Kloin, Pullum and Sag (1985)), Head Grammar (Jollard (19831)), and HeadDriven Phrase Struclure Crammar (IIPSC) (Pollard (1985a,b)). These formalisms dispense with global opere tions such as transformation, and instead cxploit local operations cach confined within a local tree. Such local operations are formulated in terms of unification

However, the ordinary unification as in frolog is insurficient, seen from both scientifie (here, alas linguistic) and enginecring points of view. The problem is that pat terns to be unfied with each other lack the capacity for carrying informition

In this paper we present a new method of unification which we call conditioned unification. 'l'he essence of the method is to deal with patterns annotated by some sort of conditions. 'These conditions are so constrained as to be cmiciently operated on, and yet to be able to carry rich enough information to rapture linguistic generalizations.

\section{2. 'lhe Problem}

Ordinary patlorns as in Prolog lack expressive power. because variables therein are simply indetcrminate and 1.hus carry almost no information. Therefore, such patlerms and unification among them are insufficient for capturing the grammatical generalization and the procossing efriciency. Inet us look at some examplos below. A grammatical calerory is assumed to be a list of features. A reature consists of a feature name and a value, and represented as a term like name (value).

The lexical entry of Finglish verb put, for instance, cannot be described as a l'rolog pattern, but needs some annotation (i.e., put_tns_psn_nmb $(T, P, N)$ ) as in (1).

(1) iexiecon(put, |tense('I), person( $\left({ }^{2}\right)$, number $\left.(N) \mid\right):-$ pul_Lns_psn_numb( $\mathrm{l}, \mathrm{l}, \mathrm{l}, \mathrm{N})$

Here, features other than tense, person, and number are omitled, and predicate put tns_psn_nmb is derined as in (2)
(2) put_ins psn_mmb(present, $P, N)$ not_ird sng $(P, N)$

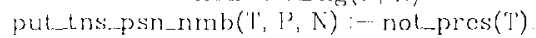

not_3rd.sng $(1 \mathrm{sl}, N)$ nol_pres(past)

not.3rd_sng(Bnd, N). not.pres(past_participle)

not_3rd.sng(3rd, plural). not_pres(base).

For a bit more compleated instance, consider the rela tionship between a syntactic gap and its filler. In (iPSG IIPSC, cte., this relationship is captured in terms of the SIASII featurc, which represents gaps. In the category of $I$ think is crazy, for example, the SlASH feature is specified as $\left|N^{\prime}\right|$. Here Slish is assumed to take as its value a list of categories. Stated below iss a simplified principle about the distribution of this feature in lypical cases

(3) In a local tree, the mother category's SIASH fealure is oblained by concatenating from left to right the SIAsil foatures of her daughters

In order to describe this principle, something nore than a mere patlern is required again:

(4) $\quad$ ocal $\operatorname{rec}([\operatorname{si} \mid \operatorname{ash}(X)\},[\operatorname{s}] \operatorname{ash}(Y)],[\operatorname{slash}(Y)])-$ append $(Y, Y, X)$

Features other than siAsfl are omitted here.

The so-called procedure altachments is the most common way of complementing the poor deseriptive capacity of ordinary patlerns for instance, you may regard the bodies of florn clauses (1) and (1) as atliched procedures

The drawhack of procedure attachment is in the fact that the only way of using the procedures is to execute them lon this reason, procodures are merely embedded in programs, rather than atlached to those patlems which these proerams operate on. "'the information which procedures contain cannol fenerally be carred around across several parlial structures cach of wheh a procedure direclly operates on, because, once a procedure is exeated, the information which it contaned is partially lost. lior instance, when lexical ontry (1) is cxploited. mut tns psn nimb ( $T, P, N)$ is executed and ' $T$ ' and $P$ are instantiated to be present and ist, respectively. Thus loft behind is the information about the other ways to instanLiate those variables.

Actual proedure altichments must be arranged so that information should nol be lost when procedures are cxecuted freeze of Prolog (Colmerauer (1982)) for instanes, is a means of this arrangement. By executing frepe $(X, \psi)$, atomic formula $\psi$ is frozen, i.e., the execution of $\psi$ is suspended until variable $X$ is instantiated. If $\psi$ contains $Y$, therefore, hopefully not, so mush information is lost when $\psi$ is executed

Nevertheloss, freeze is problematic in two respects F'irst, information can still be lost when the fromen pro cedures are execuled. Second, too much information can bo accumulated while several procedures are frozen. Suppose, for instance, that freeze $(X$, member $(X,|a, b|))$ and freeze $(Y$, member $(Y,|b, c|))$ hixe been executed. Ther, $X$ and $Y$ can be unified with each other without awakening cither procedure, In that case, the information that $X$ may be $b$ is redundant betwoen the two procedures, and the other part of information those procedures conteair is incon sistent. What one might hope here is 10 instantiate $X$ fand $Y$ ) to be $b$. If wo had excouted freeze $Y$, member $(Y, \mid c$, d) instead of freeze $(Y$, member $(Y,|b, c|)$, computational 
resources would be wasted as the price for a wrong processing.

Nter all, it is up to a programmer to take a deliberate care so that information should be efriciently transmitted across patterns. This causes several problems interwoven with one another. First, since those programs reflect the inlended order of execution, they fall to straightforwardly capture the uniformitics captured by rules or prineiples such as (3). Accordingly, programning takes much labor. Moreover, the resulting programs work efficiently only along the inilially intended order.

\section{Conditioned Unification}

\subsection{Conditioned Pallerns;}

These problems will be sctuled if we can attach information to patterns, instcad of attaching procedures to pro" grams. Here we consider that such information is carried by some conditions on variablos. Variables are then regarded as carrying some information rather than remaining simply indeterminate.

By a conditioned patlern let us refer to a pair of a pattern and a condilion on the variables contained in that pat. tern. For simplicity, assume that the condition of a conditioned pattern consists of atomic formulas of Prolog whose argument positions are filled with variables appearing in the pattern, and that the predicates heading those atomic formulas are defined in terms of florn clauses. For instance. we would like to regard the whole thing in (1) or (4) as a conditionced piatern.

\subsection{Modular Conditions}

'the conditions in conditioned patterns must not be executed or the contained information would be partially lost. l'he conditions have to be somehow joined when conditioned patterns are unified, so that the information they contain should be transmitled properly in the sense that the resulting condition is cquivalent to the logical conjunction of the input conditions and contains neither redundant nor inconsistent information. We call such a unification a conditioned unification.

$\Lambda$ simple way to reduce redundancy and inconsistency in a condition is to let cach part of each possible value of cach variable be subject to at most one constraint. I.ct us formulate this below. We say that a condition is superficially modular, when no variable appears twice in that condition. For instance, (5a) is a superficially modular condition. whereas $(5 b, c)$ are not. (Conditions are some-. times written as lists of atomic formulas.)

$$
\begin{array}{ll}
\text { a. } & {[a(X, Y), b(Z), a(U, V)]} \\
\text { b. } & {[a(X, Y), b(Y)]} \\
\text { c. } & {[a(X, Y, X)]}
\end{array}
$$

Further we say that a condition $\phi$ is modular, when all the relevant conditions are superficially modular. Jere, the relevant condilions are " $"$ and the bodies of Horn clauses reached by descending along the definitions of the predicates appearing in $\$$. A predicate is said to be modular when its definition contains only those Horn clauses whose bodies are modular conditions. A predicate is potentially modular when it is equivalent to some modular predicate.

$\Lambda$ modular condition does not impose two constraints on any one part of any variable, and therefore contains nelther redundancy nor inconsistency. Hercafter we consider that the condition in every conditioned pattern should be modular.

\section{3. lixpressive Power}

Condilioned palterns can carry rich enough information for capturing the inguistic generality. Obviously, at first, they can describe any finite set of finite patterns. For instance, (1) is regarded as a conditioned pattern with modular condition [put ths psn nmb $(T, P, N)]$. Moreover, also some recursive predicates are modular, as is demonstrated below.

(6)

$$
\begin{aligned}
\text { a. } & \text { append }([], Y, Y) \\
& \text { append }([U \mid X], Y,[U \mid Z,]):-\operatorname{append}(X, Y, Z) \\
\text { b. } & \text { sublist }([], Y) . \\
& \text { sublist }([U \mid X],[U \mid Y]):-\operatorname{sublist}(X, Y) . \\
& \text { sublist }(X,[U \mid Y]):-\operatorname{sublist}(X, Y) .
\end{aligned}
$$

Thus, (1) is also a conditioned pattern

Ilowever, some recursive predicates are not potentially modular. They include reverse (the binary predicalc which is salisficd iff its two arguments are the reversals of each other, as in reverse $([[a, b], c, d],[d, c,[a, b]])$ ), perm (the binary predicate satisfled iff its arguments are permuLations of each other, as in perm $([1,2,3],[2,1,3])$ ), subset (the binary predicate which obtains iff the first argument is a subset of the sccond, as in subset $([d, b],[a, b, c, d])$ ), cle.

Neverthcless, this causes no problem regarding natural language procossing, because potentially infinite patterns comc up only out of features such as SIASH, which do not. requirc those non-modular predicates.

\section{4. 'lhe Unifier}

Shown below is a trace of the conditioned unification between conditioned patterns (7) and (8) (here we use the same notation for conditioned patterns as for Iorn clauses). where the predicates therein have been deficd as in ( $(3)$. ('the defintions of $c 0$ and $c 3$ are not exploited.) First, we unify $[X, Y, \%, W]$ and $[A, B, C, D]$ with one another and get $X=A, Y=B, Z=C$, and $W=D$. In the cnvironment under this unifreation, the two conditions are concatenated, resulting in $[c O(X), c 1(Y, \%), c 2(\%, W)]$. The major task of this condilioned unification is lo obtain a modular condition cquivalent, to this non-modular, condition. 'l'his is the job of function modularize. Modularize calls cunction integrate, which relums an atomic formula cquivalent to the given condition. The lermination of a modularize or an integrate is indicated by $\Rightarrow$ preceding the return-value, with the same amount of indentation as the outset of this function call was indicated wilh. When an integrate calls a modularize, the alphabetic identifer of the exploited Horn clause is indicated to the left-hand side, and the temporal unification to the right-hand side. Atomic formulas made in integrate is written following $\downarrow$. Each Horn clause entered into the defintion is shown following $\uparrow$, and given an alphabetic identifer indicaled to the righl-hand side.

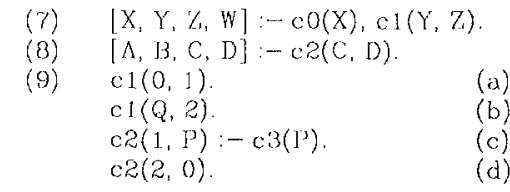

modularize $([\mathrm{co}(\mathrm{X}), \mathrm{c} 1(\mathrm{Y}, \mathrm{Z}), \mathrm{c} 2(\mathrm{Z}, W)])$

integrate $([\mathrm{cO}(\mathrm{X})])$

$\Rightarrow \mathrm{co}(\mathrm{X})$

integrate $([c 1(Y, Z), c 2(Z, W)])$

$$
\downarrow c \downarrow(Y, Z, W)
$$

(a) modularize([c2(1,W)]) $Y=0, Z=1$ integrate $([c 2(1, W)])$

$$
\downarrow 05(W)
$$

(c) modularize $([\cos (\mathrm{P})]) W=\mathrm{P}$ integrate $([\mathrm{c} 3(\mathrm{P})])$ $\Rightarrow \mathrm{c} B(\mathrm{P})$

$$
\Longrightarrow[\mathrm{c} 3(\mathrm{P})]
$$
$\Rightarrow c 5(W)$

$$
\Rightarrow[\mathrm{cs}(\mathrm{W})]
$$


$\uparrow \mathrm{c} A(0,1, W): \cdots \operatorname{ct}(W)$

(b) modulariac([o2(2,W)]) Y=Q,V=2

intcgrate $(|c 2(2, W)|)$

$$
+\cos (W)
$$

(d) modularime(l I) $W=0$

$\Rightarrow$ I]

$\hat{\cos }(0)$

$\rightarrow c 6(W)$

$\Rightarrow \mid \cos (w)\rfloor$

$\uparrow c 4(Q, 2, W):-c 6(W)$

$\Rightarrow \mathrm{C} 4(Y, \%, W)$

$\Rightarrow[\mathrm{co}(X),(\mathrm{A}(Y, Y, W)]$

We can refine the program of integrate so that it should avoid any predicate whose dofnition contains only one lforr clause. For instance, the definition of c 5 consists only of (i) Instead of (j), therefore, wo may have o $1(0,1, P):-c, 3(\nu)$ $\Lambda$ so (l) can be replaced by $4(Q, 2,0)$, based on (k)

We are able to work out recursive conditions from given recursive conditions. For example, consider how $X$ and $\%$ are unified under the condition (10), where member is defined as in (11)

(10) $|\operatorname{member}(X, Y), \operatorname{co}(Y)|$

(11) $\operatorname{member}(\Lambda,|\Lambda| B])$. member $(\Lambda,|C| B]):-\operatorname{member}(\Lambda, 13)$.

l'he trace of this unifeation is shown below, where predicale c 1 is recursively defned based on the recursive definilion of member.

modularize( $(\operatorname{mamber}(X, Y), \operatorname{co}(X) \mid)$

integrate( $(\operatorname{monber}(X, Y), c O(X) \mid)$ $\downarrow c 1(\mathrm{X}, \mathrm{Y})$

(a) modularize $([\mathrm{co}(\Lambda)]) X=\Lambda, Y=[\Lambda \mid \beta]$

$$
\text { integrate }([\operatorname{co}(\Lambda)])
$$$$
\rightarrow \operatorname{co}(\Lambda)
$$$$
\Rightarrow[00(\Lambda)]
$$$$
\uparrow \operatorname{cl}(\Lambda,[\Lambda \mid B]): \cdots \operatorname{co}(\Lambda)
$$

(b) nodulari\%e(lnomber $(\Lambda, B), \operatorname{co}(\Lambda)]) X \cdots \Lambda, Y \cdots[C \mid B]$ inlegrale $([$ member $(\Lambda, B), c O(\Lambda) \mid)$

$$
\rightarrow c 1(\Lambda, 3)
$$$$
\Rightarrow \mid c 1(\Lambda,] 3) \mid
$$$$
\uparrow c 1(\Lambda,[C \mid[B]):-c 1(\Lambda, B) \text {. }
$$

$\begin{aligned} & \Rightarrow \cos (X, Y) \\ \Rightarrow & {[\mathrm{c} 1(\mathrm{X}, \mathrm{Y})] }\end{aligned}$

It is a job of integrate to handle recursive defnition. 'l'he last integrate above recognizes that the first integrate, which is trying to define o 1, was called with the same arguments except the variable names. Hence the last integrate simply returns o $1(A, l)$, because the conlent of 01 is now being worked out under the first integrate and thus it is redundant for tho last integrate to futher examno of

It is rot always possible for the above unifier lo unify patterns under recursive conditions. For instance, il cammot unily $X$ with $Y$ under $[\operatorname{append}(X, Y, Z)]$, because the result ing condition is not potentially modular. Ilowever, such a situation does; not secm to occur in actual language procossing.

\section{Conclusion}

We have presented a now method of unification, wheh we call a conditioned unification, where pattems to bo unifed se annolated by a certain sort of eonditions on the variables which occur in those patternas. 'l'hese conditions are so restricted that thoy contain as little redundancy ass possible, and thus are always assured to be satisfiable.

rhis method has the following welcome characteristics l'irst, the patterns to be unified can carry abundant infor malion represented by the conditions hangings on them. 'The expressive capacity of these conditions is sufleient for can turing lingustic gencralisics. Second, such infommation is effoctively transmitled by intersating the conditions when palterns are anified. Unlike procedure attachments, in this connection, the information-conveying efliciency of our con ditioned unification is not aflected by the direction of the data low therefore, our conditioned unifoation $1 \mathrm{~s}$ com pletely reversible, and thus is promising as a tool for describing, grammass for both sentenece comprohension and procluation

Owing to these characteristies, our conditionod unificalion proviases a new programoning paradigm for natural langlage processing, replacing procedure attach monts which have tradionally onjoyed the ubiguty that they do not deserve

\section{References}

Brosnan, J. (cd.) (1983) The Mental Representation of Crammatical helations, MIC Press, Cambrige, Mas sacbusct.s.

Colmerauer, A. (1980) lrolog $/ 7$ lieference Manuat and theoretical Model, liRA CNIRS 363, Groupe d'Intelligoned Artificielle, Iniversité de Marsoille, Marsolle.

Gazdar, G., li. Kloin, G. K. Pullum, and T. A. Sag (1986) Gen. eralized lhrase Structure Crammar, Basil Blackwoll. Oxford.

Kay. M. (1985) "l'arsing in Functional Unfuation Gram mar." Natural language l'orsing up. 201-270, Gan. bridge liniversily l'ross, Cambridge, lingland.

Poreira, l". C. N (1980) "A Stmetur" Sharng lepresenta tion for Unificatiom based Grammar l'ormalisms,' Iroceedings of the Rird Annual Meeting of the Association for Computatianal Lingusines, Unversity of Chicafo, Chichiso, lllinois

Pollard, ( ) (1984) Ceneraltized thrase structure cram mar, llead crammars, and Natural languages, jootoral dissertation. Stimford Inivorsily, Stanford, Cait. Comila.

l'ollard. C. d. (1085a) lecture Notes on Head-1brinen thrase Structure Crammar, Conter for the Study of langlage and Information.

l'ollare, C. J. (198bb) "Phrase Strueture Geammar witioul Matarules," proceedings of the lourth Wast coast Conference on formal hmouistics, Universily of south crn California, Ios Angeles, Califorma.

I'roudin, D. and C. J l'ollard (19635) "f'arsing Hoad-brivon lhrase Slructure Grammar," lroceedings of the 23 rd Annual Meeting of the Association for Computational linguistios, Universily of Chicago, Chicago, Illinors.

Streber, S. M. (1984) "'the Dosign of a Compuler lianguage for linguistic Information," Proceedings of the loth International conference on computational linguistios, Stanford University, Stan[ord, California.

Sheber, \$. M. (1985) "Using rostricton to lixtend parsing Algorithms for Complex-Fiature-Based formalisms." Trocedings of the Dord Annual Weeting of the Assocna tion for Computational imguistics, Unversity of Chr cago, Chicago, lllinois. 